\title{
Tumor Findings Test Code
}

National Cancer Institute

\section{Source}

National Cancer Institute. Tumor Findings Test Code. NCI Thesaurus. Code C119945.

A character or string that represents the short code name of the tumor findings assessment. 